\title{
Dangerous cosmetics - criteria for classification, labelling and packaging (EC 1272/2008) applied to personal care products
}

\author{
Ursula Klaschka
}

\begin{abstract}
Background: Cosmetic products need not be classified and labelled according to the Regulation on Classification, Labelling and Packaging (CLP) in the European Union, even if they contain dangerous substances. What would happen without this exception? Would cosmetic products have to be labelled if they were treated like any other consumer product?

Results: The criteria of the CLP Regulation were applied to a selection of cosmetic product formulas in a conservative approach. All but one product contain hazardous ingredients in amounts that would lead to classification and labelling of the mixtures. $85 \%$ of the products analyzed would have to be labelled because of potential negative effects to the eye, and 52\% because of potential negative effects to the skin. The signal word WARNING would have to be on the labels of $64 \%$, DANGER would have to be on $33 \%$ of the products.

Conclusions: The results here show that it is urgent to inform consumers about the potential dangers of personal care products, because cosmetics need to be applied even with more care than any other consumer product. Classification and labelling according to the CLP Regulation is a very good means to improve the risk communication for consumers. Therefore, it is strongly recommended that the exception for cosmetic products should be repealed in the next amendment of the CLP Regulation.
\end{abstract}

Keywords: Classification and labelling, CLP Regulation, Cosmetic products, Information for the consumer, Risk communication

\section{Background}

\section{Classification, labelling and packaging}

The system of classification and labelling of hazardous substances and hazardous consumer products has proven to be a very efficient tool for risk communication. The purpose of the European Regulation on Classification, Labelling and Packaging of substances and mixtures (EC No. 1272/2008) [1] (CLP Regulation) is "providing a primary means by which the general public and persons at work are given essential information about the hazards of substances and mixtures..... This regulation should ensure a high level of protection of human health and the environment." (Preamble (1) of the CLP Regulation). Consumer products, such as glue, varnish, or washing and cleansing

Correspondence: klaschka@hs-ulm.de

University of Applied Sciences UIm, Prittwitzstr. 10, D-89075 UIm, Germany products need to be classified and labelled if they contain dangerous ingredients that render the mixture hazardous.

The CLP Regulation implements the United Nations Globally Harmonized System of Classification and Labelling of Chemicals (UN GHS) [2] in the EU und replaces the Substance and the Preparations Directives (67/548) [3] and (1999/45) [4]. The CLP Regulation came into force for substances in 2010 and will have to be implemented for mixtures in 2015.

\section{Special situation for cosmetic products}

Cosmetic products do not need to be classified and labelled Cosmetic products were excluded in the Preparations Directive and they are excluded in the CLP Regulation (Art. 1 (5)) (Table 1(A). Although the CLP Regulation implements the UN GHS, it does not take over everything as such. For example, the UN GHS does not clearly exclude cosmetic products. It only quotes the opinion of the 
Table 1 Synopsis of the various passages of the CLP regulation and the relevance for cosmetic products

\begin{tabular}{|c|c|c|}
\hline & Consequences for cosmetics & What would happen without the general exception for cosmetics? \\
\hline $\begin{array}{l}\text { General exception for } \\
\text { cosmetics (A) }\end{array}$ & $\begin{array}{l}\text { No labelling of any cosmetic } \\
\text { products. }\end{array}$ & $\begin{array}{l}\text { Many cosmetics fulfill the criteria for classification and labelling and would } \\
\text { need to be classified and labelled. }\end{array}$ \\
\hline $\begin{array}{l}\text { Special regulations for } \\
\text { containers smaller than } 125 \mathrm{ml} \\
\text { (B) }\end{array}$ & $\begin{array}{l}\text { Many cosmetic containers are } \\
\text { smaller than } 125 \mathrm{ml} \text {. }\end{array}$ & $\begin{array}{l}\text { Most cosmetic products that fulfill the criteria for classification and labelling } \\
\text { are sold in small containers. Only a small number of } \mathrm{H} \text {-statements would be } \\
\text { applied to cosmetic products in small packages. }\end{array}$ \\
\hline $\begin{array}{l}\text { Labelling of mixtures which are } \\
\text { not classified as sensitizing (C) }\end{array}$ & $\begin{array}{l}\text { Most cosmetic products contain } \\
\text { sensitizing fragrances. }\end{array}$ & Most cosmetic products would have to be labelled. \\
\hline $\begin{array}{l}\text { Stricter classification due to } \\
\text { data gaps (D) }\end{array}$ & $\begin{array}{l}\text { There is insufficient published data } \\
\text { for many cosmetic ingredients. }\end{array}$ & $\begin{array}{l}\text { The final classification of many cosmetic ingredients would be more severe } \\
\text { than in the examples listed here, as I did not consider data gaps as criteria } \\
\text { to classify cosmetics more strictly. }\end{array}$ \\
\hline $\begin{array}{l}\text { Classification of aerosol } \\
\text { dispensers (E) }\end{array}$ & $\begin{array}{l}\text { Hair spray is labelled, irrespective of } \\
\text { the general exception for cosmetics. }\end{array}$ & This regulation is not affected by the general exception for cosmetics. \\
\hline
\end{tabular}

Respective paragraphs in the CLP regulation [1].

(A) Art. 1 (5) "This Regulation shall not apply to substances and mixtures in the following forms, which are in the finished state, intended for the final user: ... (C) cosmetic products as defined in Directive 76/768/EEC".

(B) Annex I Part 1 "1.5.2. Exemptions from Article 17 [(Article 29(2)] 1.5.2.1. Labelling of packages where the contents do not exceed 125 ml 1.5.2.1.1. The $\mathrm{H}$-statements and the P-statements linked to the hazard categories listed below may be omitted from the label elements required by Article 17 where: (a) the contents of the package do not exceed $125 \mathrm{ml}$; and (b) the substance or mixture is classified in one or more of the following hazard categories: 1) Oxidising gases of category 1;2) Gases under pressure; 3) Flammable liquids of category 2 or 3; 4) Flammable solids of category 1 or 2; 5) Self-reactive substances or mixtures Types $\mathrm{C}$ to $\mathrm{F} ; 6)$ Self-heating substances or mixtures of category $2 ; 7$ ) Substances and mixtures which, in contact with water, emit flammable gases of categories 1,2 or $3 ; 8$ ) Oxidising liquids of category 2 or $3 ; 9$ ) Oxidising solids of category 2 or $3 ; 10$ ) Organic peroxides Types $C$ to F; 11 ) Acute toxicity of category 4, if the substances or mixtures are not supplied to the general public; 12) Skin irritation of category 2; 13) Eye irritation of category 2; 14) Specific target organ toxicity - single exposure of category 2 or 3 , if the substance or mixture is not supplied to the general public; 15) Specific target organ toxicity - repeated exposure of category 2, if the substance or mixture is not supplied to the general public; 16) Hazardous to the aquatic environment - Acute of category 1 ; 17) Hazardous to the aquatic environment - Chronic of category 1 or 2 ".

(C) Annex II Part 2 "2.8: Mixtures not classified as sensitizing but containing at least one sensitizing substance must be labelled according to the special rules for supplemental label elements for mixtures..... The label on the packaging of mixtures containing at least one sensitizing substance in a concentration equal or greater than $0.1 \%$... shall bear the statement: EUH208 'Contains (name of sensitizing substance). May produce an allergic reaction'”.

(D) Annex I Part 3 "3.1.3.6.2.2. In the event that an ingredient without any useable information at all is used in a mixture at a concentration of $1 \%$ or greater, it is concluded that the mixture cannot be attributed a definitive acute toxicity estimate. In this situation the mixture shall be classified based on the known ingredients only, with the additional statement that $x$ percent of the mixture consists of ingredient(s) of unknown toxicity. 3.1.3.6.2.3. If the total concentration of the ingredient(s) with unknown acute toxicity is $\leq 10 \%$ then the formula presented in section 3.1.3.6.1 shall be used. If the total concentration of the ingredient(s) with unknown toxicity is $>10 \%$, the formula presented in section 3.1.3.6.1 shall be corrected to adjust for the total percentage of the unknown ingredient(s) as follows:....".

(E) Art. 14 (2) c) "The exemptions for labelling of small packages of aerosols as flammable laid down in Directive 75/324/ EEC shall apply to aerosol dispensers" Directive 75/324/ EEC [5] Annex 2.2 "Labelling: Without prejudice to the Directives relating to the classification, packaging and labelling of dangerous substances and preparations, particularly as regards danger to health and/or the environment, any aerosol dispenser must visibly bear the following legible and indelible marking: ..... (b) Where the aerosol is classified as 'flammable' or 'extremely flammable' according to the criteria of point 1.9: - the flame symbol, in accordance with the model in Annex II to Directive 67/548/EEC; - the indication 'flammable' or 'extremely flammable', depending on the classification of the aerosol as 'flammable' or 'extremely flammable'.'.

Interorganization Programme for the Sound Management of Chemicals Coordinating Group in Art 1.1.2.4 who says “..., cosmetics, ... will not be covered by UN GHS in terms of labelling at the point of intentional intake. ... further discussion will be required to address specific application issues for some product use categories which may require the use of specialized expertise." Apart from this word-for-word quote, there is no statement in the official UN GHS text about the treatment of cosmetic products. The following general sentence is not restricted by any exceptions (in 1.1.3.1.4) "For the consumer sector, it is expected that labels will be the primary focus of GHS application."

There are additional provisions in the European CLP Regulation which are important for a potential classification of personal care products:

(1) Certain hazard and precautionary statements and pictograms need not be listed on the product label of containers if these are smaller than $125 \mathrm{ml}$ ([1]
Annex I 1.5.2.1.1, Table 1B). Shampoos, liquid soap or shower gels are examples of products sold usually in bigger containers than $125 \mathrm{ml}$, whereas most personal care products, like tooth paste, deodorants, aftershave, perfume, lip stick, or nail varnish are usually sold in smaller containers. (2) Supplemental statements on the product labels inform the consumer if the criteria for classification are not fulfilled, but information exists about a potential hazard e.g. sensitization Table $1(\mathrm{C})$ ). (3) However, you will find single cosmetic products with labels: Aerosol dispensers, such as hairspray, must be labelled for their physical hazard class as highly flammable according to EC 75/324 [5] and CLP Regulation Art.14(2)c). This labelling requirement could also mislead some consumers. They might think that cosmetic products must be labelled in general and there would be no hazard other than the flammability of hair spray. In addition, some instant nail glue products made in 
Switzerland are also labelled, although Switzerland has adopted the CLP Regulation with the exception for cosmetic products.

Table 1 gives an overview about some legal aspects in the CLP Regulation relevant for a potential classification of cosmetic products and their consequences. The last column summarizes what would happen if the general exception for cosmetics in the CLP Regulation were abolished.

\section{Is the exception for cosmetics justified?}

There are several possibilities why an exception of labelling would be justified for a certain product group. The following potential reasons are briefly discussed for cosmetic products:

1. "Cosmetic products are not dangerous." No. Many dangerous substances have been banned for personal care products. More than 13000 substances may not be used in cosmetic products according to the Cosmetics Regulation 1223/2009 [6] (Annex II, List of Substances prohibited in cosmetic products), and around 250 compounds may be used only under certain conditions (Annex III, List of substances which cosmetic products must not contain except subject to restrictions laid down.). However, the exception for cosmetic products in the CLP Regulation implies that there are mixtures which would be classified as dangerous for the human health or environment. Otherwise the exception would be superfluous. In the following, I will focus on this reasoning. I will describe which cosmetic products would be labelled if the CLP Regulation did not exclude them.

2. "Everybody knows that cosmetics are dangerous. Therefore, labels are not needed." No. Pharmaceuticals for example do not need to be classified and labelled because everybody should know that they have biological effects and must be used with special care in minimum doses. This reasoning for pharmaceuticals is not applicable to cosmetics, as most consumers do not associate health and environmental risks with their daily used personal care products.

3. "Personal care products are used in such low doses that it is irrelevant whether the mixtures are dangerous." No. The classification and labelling scheme is based on inherent properties of the components. It is not based on a risk assessment where exposure is compared to effects. Furthermore, personal care products are applied directly to the surface of the human body frequently and in relatively large amounts [7].

4. "It is sufficient that the ingredients are listed on the containers of cosmetics." No. It cannot be assumed that the general public can look up the classifications and labelling of the ingredients and derive the classification of the mixture themselves before they buy and use these products. Proper consumer information would include the labels as for any other consumer product.

5. "Ingredients are not clearly defined, such as essential oils, which would impede classification and labelling."

No. The quality standard of cosmetic products is usually very high, and the ingredients are usually clearly identifiable. Components which are natural mixtures or result from chemical synthesis may be composed of many chemical substances, but this does not affect potential classification and hazard assessment in general.

6. "Labelling would be a danger for manufacturers' interests and company secrets." No. The classification and labelling of their products should not affect producers of personal care products in a much different way than producers of e.g. washing and cleansing products or paints and varnishes. Companies' intellectual property rights are protected. The list of ingredients on the containers together with the frame formulations [8] and the Classification and Labelling Inventory [9] (C\&L Inventory) might allow to derive rough classifications of the products for someone who makes the effort already now.

7. "Labelling would lead to a decrease in sales of personal care products." Probably not. It is difficult to isolate labelling as one factor that would affect the sales numbers for a consumer product. E.g. there is no information whether sales of washing and cleansing products went down because of the labelling. Health warnings on tobacco products seem to have affected neither consumption nor sales. If cosmetic products were labelled, this might lead to a shift to products with less hazard pictograms, and such an effect should be in everybody's interest.

8. "The image of beauty and wellness that many consumers associate with cosmetics would be endangered when the mixtures are labelled as dangerous." Probably not. Some consumers would certainly be surprised to see personal care products labelled as dangerous. However, consumers know about the deleterious effects of alcoholic beverages or cigarettes and they still consume these products. The general public has the right to be informed about the reality by correct hazard pictograms.

9. "The classification of single substances by various producers is not consistent. Therefore, product classification is not feasible." No. This argument would be valid for classification and labelling of all products and would make classification in general impossible. Instead, this argument would plead for a more consistent classification of ingredients. 
There might be further reasons why an exception for cosmetics was taken up in the CLP Regulation, but the arguments listed here that plead against this exception are strong.

\section{Results}

The classifications presented here tend to be underclassifications to outline the best case, not the worst case. As I did not have the comprehensive data base like the producers of the respective products, I deliberately made the following assumptions which may lead to less severe classifications: (1) Where self classifications of various companies differed in several $\mathrm{H}$-statements, I used the classification which the majority of companies agreed upon, which was usually not the most severe classification. (2) In most basic recipes no specific chemical names were given for preservatives, colorants, pigments or fragrances. In these cases I did not consider them at all, although it is known that most of them are hazardous substances. (3) I did not consider any potential contaminations, impurities or stabilizers/preservatives as part of an ingredient as I assume that they are present below the cut off values ([1] Annex I 1.1.4.1). (4) I pretended that all properties of all ingredients are known and did not make use of the possibility to subtract substances with unknown properties ([1] Annex I 3.1.3.6.2). However, when no information could be retrieved for more than $20 \%$ of the total product, products were not considered further. Most decorative cosmetic products which contained up to $10 \%$ of unnamed pigments reached this limit and could not be analyzed further. Also natural ingredients pose problems for the correct classification, as the available information is scanter than for synthetic ingredients. Some ingredients do not have a CAS or EC number and could not be investigated further. Products which contained more than $80 \%$ water were not considered if half of the remaining ingredients were unclear. (5) I pretended that the $\mathrm{pH}$ values are in a medium range and not extremely low or high. Therefore, I did not consider pH-effects of mixtures. (6) I pretended that diluted ingredients are diluted with water and not with any other solvent. (7) I had no information about the physical properties like thermal stability, heat of combustion, flash point or boiling point of the mixtures. I assumed that these properties were not crucial for cosmetic products and considered only the physical hazards of aerosol dispensers. (8) When the components were heated to allow chemical reactions before preparation of the final product (e.g. for soap production) I considered neither the raw material nor the reaction products.

On this background producers might obtain different results using the precise composition of their own products and the data of their specific ingredients without a deliberate under-classification as I had to do here.

Criteria for classification and labelling were applied to 41 cosmetic products as described in the Methods. Eight products could not be dealt with further due to insufficient data. Classifications and labels of some products are illustrated in Figure 1 and the resulting H-statements of all 33 products are compiled in Table 2 (A). One product (3\%) would not need to be classified and labelled. None of the products would need to be labelled with GHS01 (explosive), GHS03 (oxidizing), GHS04 (compressed gas) or GHS06 (acutely toxic). Five products (15\%) would need to be labelled with GHS05 (corrosive), 25 products (76\%) with GHS07 (acute hazard) and 7 products (21\%) with GHS08 (chronic hazard) and one product (3\%) with GHS09 (environmental hazard). The signal word WARNING would have to be on the labels of 21 products (64\%), DANGER would have to be on 11 products (33\%).

The list in Figure 1 shows some examples of the 41 products analyzed. The classifications tend to be less severe as illustrated in the text. According to Article 18 of the CLP Regulation ". ... the identity of all substances in the mixture that contribute to the classification of the mixture as regards acute toxicity, skin corrosion or serious eye damage, germ cell mutagenicity, carcinogenicity, reproductive toxicity, respiratory or skin sensitization, specific target organ toxicity (STOT) or aspiration hazard" must be written on the label (see first column). Substances responsible for other hazard statements need not be listed by names.

The most frequently allocated H-statement was H319 'Causes serious eye irritation.' (61\%), followed by H315 'Causes skin irritation.' (33\%). 85\% of the products would have to be labelled because of potential negative effects to the eye (H318, H319 and H314). 52\% of the products would have to be labelled because of potential negative effects to the skin (H314, H315 and H317).

Labels of classified products should also bear the precautionary statements (P-statements). I listed the respective $\mathrm{P}$-statements which the $\mathrm{H}$-statements in Figure 1 would entail Table 2(B). Child resistant fastenings and tactile warnings would be required for products classified as 'Causes severe skin burns and eye damage.'. Not more than six P-statements should be applied to the container of a product out of the selection given in Table 2(B).

\section{Discussion}

\section{Cosmetics contain hazardous ingredients}

All products scrutinized contain hazardous ingredients. In many cases, the concentrations of a hazardous chemical in the products were many times higher than the thresholds for classification. The 'eye zone cream' is the only product in the selection that would not need to be classified and labelled. However, it contains $71.9 \%$ water as solvent for the active ingredients. If in the course of 


\begin{tabular}{|c|c|c|}
\hline Product & $\begin{array}{c}\text { Pictograms and } \\
\text { signal word }\end{array}$ & H statements \\
\hline Eye zone cream & & - \\
\hline Baby shampoo & ! WARNING & Causes serious eye irritation. \\
\hline Mild roll on deodorant & ! ${ }_{\text {WARNING }}$ & Causes serious eye irritation. \\
\hline Liquid syndet & WARNING & Causes serious eye irritation. \\
\hline $\begin{array}{l}\text { Massage oil carbon free } \\
\text { contains Olea Europaea fruit oil. }\end{array}$ & & May cause an allergic skin reaction. \\
\hline $\begin{array}{l}\text { Nail glue } \\
\text { contains Ethyl Cyanoacrylate. }\end{array}$ & IING & $\begin{array}{l}\text { Causes skin irritation. } \\
\text { Causes serious eye irritation. } \\
\text { May cause respiratory irritation. }\end{array}$ \\
\hline After shave lotion & RNING & Causes serious eye irritation. \\
\hline $\begin{array}{l}\text { Gel toothpaste } \\
\text { contains Silica. }\end{array}$ & & $\begin{array}{l}\text { Causes skin irritation. } \\
\text { Causes serious eye irritation. } \\
\text { May cause respiratory irritation. }\end{array}$ \\
\hline Hand cream & & $\begin{array}{l}\text { Causes skin irritation. } \\
\text { Causes serious eye irritation. }\end{array}$ \\
\hline Hair spray extra strong & & $\begin{array}{l}\text { Highly flammable liquid and } \\
\text { vapour. } \\
\text { Causes serious eye irritation. }\end{array}$ \\
\hline $\begin{array}{l}\text { Oxidative hair dye } \\
\text { contains Cocamide DEA, Lauramide } \\
\text { DEA, Ethanolamine. }\end{array}$ & & $\begin{array}{l}\text { Causes severe skin burns and eye } \\
\text { damage. } \\
\text { Causes serious eye damage. }\end{array}$ \\
\hline $\begin{array}{l}\text { Liquid soap } \\
\text { contains Sodium Laureth Sulfate, } \\
\text { Cocamide DEA. }\end{array}$ & & $\begin{array}{l}\text { Causes serious eye damage. } \\
\text { Causes skin irritation. } \\
\text { Harmful if swallowed. }\end{array}$ \\
\hline $\begin{array}{l}\text { After shave balm } \\
\text { contains Cyclomethicone. }\end{array}$ & WARNING & $\begin{array}{l}\text { Suspected of damaging fertility or } \\
\text { the unborn child. }\end{array}$ \\
\hline $\begin{array}{l}\text { Alcohol free cologne } \\
\text { contains Cyclomethicone. }\end{array}$ & RNING & $\begin{array}{l}\text { Suspected of damaging fertility or } \\
\text { the unborn child. }\end{array}$ \\
\hline Insect repellent cream & RNING & $\begin{array}{l}\text { Suspected of damaging fertility or } \\
\text { the unborn child. }\end{array}$ \\
\hline $\begin{array}{l}\text { Massage oil } \\
\text { contains Paraffinum liquidum. }\end{array}$ & GER & $\begin{array}{l}\text { May be fatal if swallowed and } \\
\text { enters airways. }\end{array}$ \\
\hline $\begin{array}{l}\text { Shaving cream } \\
\text { contains Petrolatum. }\end{array}$ & DANGER & $\begin{array}{l}\text { Causes skin irritation. } \\
\text { May cause cancer. }\end{array}$ \\
\hline $\begin{array}{l}\text { Baby skin protective gel } \\
\text { contains Paraffinum liquidum. }\end{array}$ & & $\begin{array}{l}\text { Causes skin irritation. } \\
\text { Causes serious eye irritation. } \\
\text { May be fatal if swallowed and } \\
\text { enters airways. }\end{array}$ \\
\hline $\begin{array}{l}\text { Perfume } \\
\text { contains Diethylphthalate, p-tert-butyl } \\
\text { methylhydrocinnamal, Benzyl }\end{array}$ & $\langle\overrightarrow{!}\rangle\langle\underline{\text { DANGER }}$ & $\begin{array}{l}\text { Causes skin irritation. } \\
\text { May cause an allergic skin reaction. } \\
\text { Causes serious eye damage. }\end{array}$ \\
\hline $\begin{array}{l}\text { salicylate, } \\
\text { Hydroxymethylpentylcyclohexene } \\
\text { carbaldehyde, Eugenol, Citronellol, } \\
\text { alpha Ionone. }\end{array}$ & & $\begin{array}{l}\text { May cause allergy or asthma } \\
\text { symptoms or breathing difficulties } \\
\text { if inhaled. } \\
\text { Toxic to aquatic life with long } \\
\text { lasting effects. } \\
\end{array}$ \\
\hline
\end{tabular}

Figure 1 Classification and labelling of cosmetic products, on the supposition that the exception in the CLP Regulation would not be valid.

application near the eye, half of the water amount evaporated, the product would have to be classified as 'Causes skin irritation. Causes serious eye irritation.' and labelled with the GHS07 pictogram (acute hazard). It is interesting to note that even some liquid products which contain more than $50 \%$ water would need to be classified. There are products where less than $10 \%$ of the ingredients were considered for classification and labelling, the rest being water or substances with unclear toxicity, which would have to be classified as mixture. Two products for the same purpose can be classified very differently, e.g. one insect repellent would have to be classified as 'Causes serious eye irritation.' and 'May cause an allergic skin reaction.', the other as 'Suspected of damaging fertility of the unborn child.' One massage oil is classified as 'May be fatal if swallowed and enters airways.', whereas the so-called carbon-free massage oil is classified as 'May cause an allergic skin reaction.'.

The following substances were ingredients in the products under scrutiny here, but their amounts stayed below the thresholds for labelling the mixtures: Several products contain ingredients which were classified as 'Toxic if swallowed.' (e.g. Thioglycolic Acid) or 'Harmful if swallowed.' (e.g. Sodium Laureth Sulfate, PVP/VA Copolymer or Calcium Thioglycolate). Substances classified as 'Harmful if inhaled.' were e.g. PEG-40 Hydrogenated Castor Oil which was for example part of the baby shampoo. Substances classified as 'May cause respiratory 
Table 2 Compilation of H-statements and P-statements attributed to the cosmetic product formulas analyzed

\begin{tabular}{|c|c|c|c|c|c|}
\hline \multirow[t]{2}{*}{ H-statements } & \multirow{2}{*}{$\begin{array}{l}\text { A) Number } \\
\text { of products } \\
\text { (percentage) }\end{array}$} & \multicolumn{4}{|c|}{ B) Respective P-statements } \\
\hline & & Prevention & Response & Storage & Disposal \\
\hline no H-statements & $1(3)$ & & & & \\
\hline H225 Highly flammable liquid and vapour. & $2(6)$ & $\begin{array}{l}\text { P210 P233 P240 } \\
\text { P241 P242 P243 } \\
\text { P280 }\end{array}$ & P303+P361+P353 P370+P378 & $\begin{array}{l}\mathrm{P} 403 \\
+\mathrm{P} 235\end{array}$ & P501 \\
\hline H302 Harmful if swallowed. & $2(6)$ & P264 P270 & P301+P312 P330 & - & P501 \\
\hline $\begin{array}{l}\text { H304 May be fatal if swallowed and enters } \\
\text { airways. }\end{array}$ & $2(6)$ & - & P301+310 P331 & P405 & P501 \\
\hline $\begin{array}{l}\text { H314 Causes severe skin burns and eye } \\
\text { damage. }\end{array}$ & $2(6)$ & P260 P264 P280 & $\begin{array}{l}\text { P301+P330+ P331 P303+P361+P353 P363 } \\
\text { P304+P340 P310 P321 P305+P351+P338 }\end{array}$ & P405 & P501 \\
\hline H315 Causes skin irritation. & $11(33)$ & P264 P280 & P302+P352 P321 P332+P313 P362 & - & - \\
\hline H317 May cause an allergic skin reaction. & $4(12)$ & P261 P272 P280 & P302+P352 P333+P313 P321 P363 & - & P501 \\
\hline H318 Causes serious eye damage. & $6(18)$ & P280 & P305+P351+P338 P310 & - & \\
\hline H319 Causes serious eye irritation. & $20(61)$ & P264 P280 & P305+P351+P338 P337+P313 & - & - \\
\hline $\begin{array}{l}\text { H334 May cause allergy or asthma } \\
\text { symptoms or breathing difficulties if } \\
\text { inhaled. }\end{array}$ & $1(3)$ & P261 P285 & P304+P341 P342+P311 & - & P501 \\
\hline H335 May cause respiratory irritation. & $2(6)$ & P261 P271 & P304+P340 P312 & $\begin{array}{l}\text { P403 } \\
+P 233 \\
\text { P405 }\end{array}$ & P501 \\
\hline H350 May cause cancer. & $1(3)$ & P201 P202 P281 & P308+P313 & P405 & P501 \\
\hline $\begin{array}{l}\text { H361 Suspected of damaging fertility or the } \\
\text { unborn child. }\end{array}$ & $3(9)$ & P201 P202 P281 & P308+P313 & P405 & P501 \\
\hline $\begin{array}{l}\text { H411 Toxic to aquatic life with long lasting } \\
\text { effects. }\end{array}$ & $1(3)$ & P273 & P391 & - & - \\
\hline
\end{tabular}

A) The percentage indicated is based on the number of products where the classification could be performed ( 33 out of 41$)$.

B) P-statements assigned to the respective hazard statements according to the CLP-Regulation. Note that P-statements need not be written on small packages according to the small quantity exception.

P201: Obtain special instructions before use. P202: Do not handle until all safety instructions have been read and understood. P210: Keep away from heat/sparks/open flames/hot surfaces - No smoking. P233: Keep container tightly closed. P240: Ground/bond container and receiving equipment. P241: Use explosion-proof electrical/ventilating/lighting/. . ./ equipment. P242: Use only non-sparking tools. P243: Take precautionary measures against static discharge. P260: Do not breathe dust/fume/gas/mist/vapours/spray. P261: Avoid breathing dust/fume/gas/mist/vapours/spray. P264: Wash ...... thoroughly after handling. P270: Do no eat, drink or smoke when using this product. P271: Use only outdoors or in a well-ventilated area. P272: Contaminated work clothes should not be allowed out of the workplace. P273: Avoid release to the environment. P280: Wear protective gloves/protective clothing/eye protection/face protection. P285: In case of inadequate ventilation wear respiratory protection. P301+P312: IF SWALLOWED: Call a POISON CENTER or doctor/physician if you feel unwell. P301+P330+ P331: IF SWALLOWED: rinse mouth. Do not induce vomiting. P302+ P352: IF ON SKIN: wash with plenty of soap and water. P303+P361+P353: IF ON SKIN (or hair): Remove/Take off immediately all contaminated clothing. Rinse skin with water/shower. P304+P340: IF INHALED: Remove victim to fresh air and keep at rest in a position comfortable for breathing. P304+P341: IF INHALED: If breathing is difficult, remove victim to fresh air and keep at rest in a position comfortable for breathing. P305+351+338 - IF IN EYES: Rinse cautiously with water for several minutes. Remove contact lenses, if present and easy to do. Continue rinsing. P308 + P313: IF exposed or concerned: Get medical advice/attention. P310: Immediately call a POISON CENTER or doctor/physician. P312: Call a POISON CENTER or doctor/physician if you feel unwell. P321: Specific treatment (see ... on this label). P330: Rinse mouth. P333+ P313: If skin irritation or rash occurs: get medical advice/attention. P337+P313: If eye irritation persists: Get medical advice/attention. P342+P311: If experiencing respiratory symptoms: call a POISON CENTRE or doctor/physician. P362: Take off contaminated clothes and wash before reuse. P363: Wash contaminated clothing before reuse. P370+P378: In case of fire: Use for extinction. P391: Collect spillage. P403: Store in a well-ventilated place. P403+P235: Store in a well-ventilated place. Keep cool P405: Store locked up. P501: Dispose of contents/container to an approved waste disposal plant.

irritation.' were present, but only the sum of these ingredients would have led to a classification of the mixture, not the single substances. Substances present in products of the retail shops, where the exact percentage in the final product is unknown to the author, were for example Coumarin which is classified among other $\mathrm{H}$ statements with 'May cause damage to organs.' or Laureth-4 classified among other $\mathrm{H}$-statements as 'May cause respiratory irritation.'.

According to the CLP Regulation, mixtures which contain an ingredient without any usable information must be labelled with the additional statement " $x$ percent of the mixture consists of ingredient(s) of unknown toxicity" ([1] Annex I Table 2.1.3 Note 2). This would have to be applicable to several cosmetic products.

According to the CLP Regulation, experiences made in epidemiological data and experiences from occupational data or accident databases should be taken into account. In the case of cosmetic products the information gathered by poison centers would be very precious for the classification process. This is one example where a better coordination between the Cosmetics Regulation and the CLP Regulation 
would be very helpful [10]. When evidence in humans indicates problems with certain products, but the criteria for the regular $\mathrm{H}$-statements are not met, supplemental hazard information should then be written on the container of such products. For cosmetic products this might be, e.g. EUH066 - 'Repeated exposure may cause skin dryness or cracking.', EUH070 - 'Toxic by eye contact.', EUH071 - 'Corrosive to the respiratory tract.' ([1] Annex II Part 1). However, due to the general exception of the CLP Regulation this supplemental hazard information is not implemented for cosmetic products.

\section{Sensitizers}

The number of products labelled as sensitizing is presumably underestimated in the product sample here (Figure 1 and Table 2), because quantitative information about the content of specific sensitizing fragrances were not available and did therefore not influence the classification of the product.

Most cosmetic products contain fragrances, many of which are sensitizers [11-14]. It seems to be rather difficult to produce scented personal care products with fragrances that are not labelled. I found that out of 111 fragrances frequently applied in cosmetics and washing and cleansing products 106 were classified in the C\&L Inventory. Most of them are skin sensitizers or eye irritants. Also natural substances can be sensitizers and irritants, e.g. essential oils. Some products consist of a large fraction of fragrances, for example aftershave lotion contains $10 \%$ fragrances. Normally, mixtures which are not classified as sensitizing but contain at least one sensitizing substance in a concentration equal or greater than $0.1 \%$ must bear the supplemental label EUH208 'Contains (name of sensitizing substance) ... May produce an allergic reaction.' ([1] Annex II Part 2 2.8) Table 1(C). This supplemental label element would be relevant for most cosmetic products, but it is again not applied to them because they are excluded from the CLP Regulation in general.

\section{Carcinogens, mutagens and substances toxic to reproduction (CMR substances)}

Preamble (32) of the new Cosmetics Regulation 1223/2009 says that CMR substances should be prohibited, but there are exceptions for these substances where their "use has been found safe by the SCCS" (Scientific Committee for Consumer Safety). The number of cosmetic products analyzed here which contained substances classified as carcinogenic, mutagenic or toxic for reproduction (CMR) is small. Mutagens (such as m-Phenylenediamine), carcinogens (such as Carbomer) or substances toxic for reproduction (such as Cyclomethicone) were part of the formulas scrutinized, but they usually stayed below the concentration thresholds for labelling and classification of the mixture. Many substances used in these formulas were classified as CMR substance in the C\&L Inventory by a minority of notifiers, but these classifications were not considered here. Butylphenyl methylpropional classified as 'Suspected of damaging fertility or the unborn child.' is a frequently used masking agent present in products sold in retail shops, where the exact percentage in the final product is not known to the author.

\section{Substances toxic for the aquatic environment}

Cosmetic products are still underestimated by aquatic ecotoxicologists even as their predominant discharge is via waste water [15]. Some ingredients in the products discussed here were classified due to their aquatic toxicity, e.g. Cocamidopropyl Betaine or Lauryl Alcohol, but the amounts of these substances in the mixtures stayed usually below the thresholds for classification as dangerous to the environment. The only product classified as dangerous for the environment was perfume.

\section{Practicability of the P-statements}

The P-statements Table 2(B) should help to reduce the risks for the consumers. It becomes evident that some P-statements would ask for different user behaviour or rather for a different formula of the respective personal care product to avoid the need for these P-statements. These Pstatements are for example: P260: 'Do not breathe dust/ fume/gas/mist/vapours/spray.' P271: 'Use only outdoors or in a well-ventilated area.' P272: 'Contaminated work clothes should not be allowed out of the workplace.' P280: 'Wear protective gloves/protective clothing/eye protection/ face protection.' P303+P361+P353: 'IF ON SKIN (or hair): Remove/Take off immediately all contaminated clothing. Rinse skin with water/shower.' P304+P340: 'IF INHALED: Remove victim to fresh air and keep at rest in a position comfortable for breathing.' P405: 'Store locked up.'

\section{Cosmetic products are unique}

Cosmetic products can be considered as safer compared to other consumer products due to the following aspects: (1) Many hazardous substances are prohibited or restricted according to the Cosmetics Regulation (see above). (2) Most personal care products are diluted in water. (3) The number of people suffering from direct negative effects due to cosmetic products is relatively low. In Germany, around $2-4 \%$ of the German population suffer from contact allergy to the fragrance mix 1 [16]. However, it must be assumed that the number would be higher, if also other fragrance compounds were tested. In addition, skin sensitization is an effect where the cause-effect can be detected relatively easily compared to other effects, like reproduction toxicity. This could indicate that the number of unrecorded cases of persons suffering from effects of cosmetic ingredients might be larger. 
On the other hand, the risks posed by cosmetic products can also be larger compared with other consumer products due to the following reasons: (1) Repeated exposure increases the hazard ([1] Annex VI Part 1 1.2.1.), which is clearly the case for cosmetic products since many of them are used daily, such as tooth paste, soap or shower gel. (2) Cosmetic products are applied intentionally directly on the body surface and lead therefore to a higher exposure compared with most other consumer products. Leave-on products such as lotions or decorative cosmetics should be differentiated from rinse-off products such as shower gels or shampoos. (3) Most consumers use several cosmetic products, not only one single product everyday, which increases the exposure. (4) Solvents in cosmetic products increase fat solubility and therefore skin penetration. (5) Combined exposure of an allergen with a detergent e.g. in washing liquids can increase the allergic reaction [19]. (5) There are further interactions of substances, e.g. musk compounds are known to inhibit cellular xenobiotic export systems [17]. (6) Cross-reaction is known e.g. for some fragrances which are contact allergens [18,19]. (7) Many ingredients are not stable, especially in light and at warm temperatures. The metabolites can be more toxic than the original compounds. An example for this case is D-Limonene with a low allergenic potency that can be oxidized by air to strong allergens [20-22]. Further examples are carcinogenic nitrosamines which can be contaminants or reaction products of triethanolamin and Cocamide DEA, frequently used components in decorative eye cosmetics [23]. Cosmetics have been demonstrated to be the cause of contact allergies and many of them contain acids, bases, inorganic salts, aldehydes, and surfactants, substances which can be corrosive or irritant at concentrations $<1 \%$ and would need to be considered with special care according to the CLP Regulation ([1] 3.2.3.3.4.1). (9) Cosmetic products are mainly discharged via waste water. Therefore, their toxicity to aquatic organisms is of greater relevance than for many other consumer products. (10) The products under scrutiny here correspond to the Cosmetic Regulation [6]. However, not all products in the retail shops comply with the requirements laid down there. Many products have to be withdrawn from the market because the levels of hydroquinone, methyl metacrylate, carbamide peroxide, hydrogen peroxide, formaldehyde, di-n-butylphthalate, di(2-ethylhexyl)phthalate or heavy metals were too high [24]. It is interesting to note that microbiological contamination is another frequent reason why cosmetic products need to be withdrawn [24].

The comparison of personal care products with other consumer products shows that special properties of cosmetics ask for even more caution.

Action was taken recently to reduce the hazardous potential for a different product group: In the new toys directive [25] the thresholds for labelling sensitizing fragrances have been lowered ( $0.01 \%$ compared to $0.1 \%)$, for carcinogenic substances the threshold is now $0.0005 \%$ compared to $0.1 \%$. This shows that there was concern about negative effects at these low concentrations [26]. More progress for a better consumer protection is also needed for personal care products.

\section{Delusive containers}

Cosmetic industry is very successful in creating attractive containers. Many decorations on containers of personal care products imply beauty, health and well-being. Considering their hazardous potential it might be questioned whether this goes along with Art 34 a (2) in the CLP Regulation which says: "Packaging containing a hazardous substance or a mixture supplied to the general public shall not have either a shape or design likely to attract or arouse the active curiosity of children or to mislead consumers, ..."

\section{Conclusions and recommendations Cost-benefit analysis}

Cosmetics are beneficial: They play an important role for the personal hygiene (e.g. shampoo, soap or toothpaste), for skin care and protection (e.g. sun protection products), they are important for the well-being (e.g. shaving products, body lotion) or attractiveness (e.g. deodorants). These benefits go along with unpleasant properties such as the hazards described here or the risk of microbiological contamination. Labelling might lead to a shift to less hazardous specimens and would therefore help to reduce the negative aspects and maintain the benefit of cosmetic products. The labelling should be transparent and honest. It would not make sense if producers diluted products with water to avoid labelling.

\section{Cosmetic products should be labelled and classified: abolishment of the exception}

As long as a decent risk communication for cosmetic products is not guaranteed by the Cosmetics Regulation [6], the exception in the CLP Regulation should be abolished. This amendment of the CLP Regulation would best be made before mixtures will have to be classified and labelled according to the CLP Regulation in 2015.

\section{Amendment of the small quantity exception}

An abolishment of the labelling exception for cosmetic products would lead to a regular labelling requirement for containers bigger than $125 \mathrm{ml}$, e.g. most shampoos, shower gels or body lotions. Many cosmetic products which are sold in containers smaller than $125 \mathrm{ml}$ would still not have to be labelled regularly because of the small quantity exception, which reads that only certain $\mathrm{H}$-statements need to be written on the labels (see Table 1). This implies that for example skin irritation (category 2) and eye irritation (category 2) would not 
have to be written on the label of small containers. For better consumer information, the small quantity exception should be amended so that cosmetic products should be labelled and classified regularly, also when they are sold in smaller packages.

\section{Consumers` right to know}

Many consumers trust that personal care products are perfectly safe and do not pose any hazard. They should be informed and they should learn that cosmetic products might be hazardous. This would be one element of a successful risk reduction strategy.

\section{Methods}

The classification and labelling of personal care products was derived by application of the criteria given in the CLP Regulation. Bridging principles were not relevant as no information about comparable cosmetic products tested and classified as mixtures was available. 41 cosmetic products were selected from a wide range of product groups (e.g. $[27,28])$ : baby skin product (2), after shave (2), shaving cream, deodorant (4), toothpaste (2), shampoo (2), hand and body lotion, shower gel, liquid soap and syndet, eye zone cream, massage oil, carotene skincare gel, all purpose cream, basic cream, hand cream, emulsion with panthenol, massage oil, hair spray (2), oxidative hair dye formula, bleaching lotion, depilatory cream, cold wave solution, mascara (2), lipstick (2), face make up remover, nail glue, perfume, alcohol free cologne, insect repellent (2). The number of ingredients ranged from 41 (perfume) to a single one (nail glue). The formulas are basic recipes for standard products and correspond to lists of ingredients of products in German retail shops and cosmetic frame formulations [8]. The present selection of products is meant to illustrate the situation with some examples and it is not meant to be complete nor representative. The information on properties necessary for classification and labelling of all ingredients were compiled from data accessible to the general public. Preferentially harmonized classifications were used in the current C\&L Inventory [9]. The classifications of substances registered according to REACH were compared with the classifications in the C\&L Inventory. Most substances which are used more or less exclusively in cosmetics have not been registered according to REACH, whereas cosmetic ingredients used also in other applications like e.g. glycerol, hydrogen peroxide, isododecane, isopropanol, or phosphoric acid are registered. The recently installed cosmetic products notification portal according to the Cosmetics Regulation 1223/2009 [6] is not open for the general public and could not be used. The names used here are the INCI names [29].

For many chemicals, especially those with low production volumes, not all toxicological and ecotoxicological standard tests were performed, so that the published information might not cover all relevant risks. Several compounds are not classified in the C\&L Inventory, either because no hazardous properties were detected for the substance or because the substance was not scrutinized for its hazardous properties yet. Many cosmetic ingredients are produced in small production volumes (e.g. 1-10t/y). Data requirements for these substances according to REACH are rather small, so that the data might not be sufficient to decide about a classification.

\section{Competing interests}

The author declares no competing interests.

Received: 24 July 2012 Accepted: 10 October 2012

Published: 29 November 2012

\section{References}

1. Regulation No $1272 / 2008$ of the European Parliament and of the Council of 16 December 2008 on classification, labelling and packaging of substances and mixtures, amending and repealing Directive 67/548/EEC and 1999/45/EC and amending Regulation (EC) No 1907/2006. http://eurlex.europa.eu/LexUriServ/LexUriServ.do?uri=CELEX:32008R1272:en:NOT.

2. United Nations Globally Harmonized System of Classification and Labelling of Chemicals (UN GHS). http://www.unece.org.

3. Council Directive $67 / 548 /$ EEC of 27 June 1967 on the approximation of laws, regulations and administrative provisions relating to the classification, packaging and labelling of dangerous substances. Off J P 196, 16/8/1967, as amended by Commission Directive 2001/59/EC of 6 August 2001 adapting to technical progress for the 28th time Council Directive 67/548/EEC on the approximation of the laws, regulations and administrative provisions relating to the classification, packaging and labelling of dangerous substances. Off J L 225, 12/8/2001. http://eur-lex. europa.eu/LexUriServ/LexUriServ.do?uri=CELEX:31967L0548:en:NOT.

4. Council Directive 1999/45/EC concerning the approximation of the laws, regulations and administrative provisions of the Member States relating to the classification, packaging and labelling of dangerous preparations. Off J L 200. http://eur-lex.europa.eu/LexUriServ/LexUriServ.do? uri=CELEX:31999L0045:en:NOT

5. Council Directive 75/324/EEC of 9.6.1975 on the approximation of the laws of the Member States relating to aerosol dispensers, OJ L 147. http://eur-lex.europa.eu/LexUriServ/LexUriServ.do?uri=CELEX:31975L0324:en: NOT.

6. Regulation 1223/2009 of the European Parliament and of the Council on Cosmetic Products. http://eur-lex.europa.eu/LexUriServ/LexUriServ.do? uri=OJ:L:2009:342:0059:0209:en:PDF

7. Lorenz C, von Goetz N, Scheringer M, Wormuth M, Hungerbühler K: Potential exposure of German consumers to engineered nanoparticles in cosmetics and personal care products. Nanotoxicology 2011, 5:12-29.

8. Cosmetic Frame Formulations. European Association of Poison Centres and Clinical Toxicologists / European Cosmetic Toiletry and Perfumery Association. 2000, http://www.poisoncentre.be/IMG/pdf/ CosmeticFrameFormulations2000_FullVersion_1_.pdf.

9. C\&L Inventory. http://echa.europa.eu/web/guest/information-on-chemicals/ cl-inventory-database.

10. De Groot R, Brekelmans P, Herremans J, Meulenbelt J: The changes in hazard classification and product notification procedures of the new European CLP and Cosmetics Regulations. Clin Toxicol 2010, 48(1):28-33.

11. Klaschka U: Risk management by labelling 26 fragrances? - Evaluation of Article 10 (1) of the seventh amendment (Guideline 2003/15/EC) of the cosmetic directive. J Hyg Environ Health 2010, 213:308-320.

12. Yazar K, Boman A, Lidén C: Potent skin sensitizers in oxidative hair dye products on the Swedish market. Contact Dermatitis 2009, 61:269-275.

13. Yazar K, Johnsson S, Lind M-L, Boman A, Lidén C: Preservatives and fragrances in selected consumer-available cosmetics and detergents. Contact Dermatitis 2010, 64:265-272. 
14. Yazar K, Boman A, Lidén C: p-Phenylenediamine and other hair dye sensitizers in Spain. Contact Dermatitis 2011, 66:27-32.

15. Ternes AT, Knacker T, Oehlmann J: Körperpflegemittel in der aquatischen Umwelt. Eine bisher vernachlässigte Stoffgruppe. UWSZ-Z Umweltchem Ökotox 2003, 15(3):169-180.

16. Schnuch A, Uter W, Geier J, Gefeller O: Epidemiology of contact allergy: an estimation of morbidity employing the clinical epidemiology and drug utilisation research (CE-DUR) approach. Contact Dermatitis 2002, 47:32-39.

17. Luckenbach T, Epel D: Nitromusk and polycyclic musk compounds as long-term inhibitors of cellular xenobiotic defense systems mediated by multidrug transporters. Environ Health Perspect 2005, 113:17-24.

18. Schnuch A, Uter W, Geier J, Lessmann H, Frosch P: Sensitization to 26 allergens to be labelled according to current European regulation. Results of the IVDK and review of the literature. Contact Dermatitis 2007, $57: 1-10$.

19. Heydorn S, Andersen KE, Johansen JD, Menne T: A stronger patch test elicitation reaction to the allergen hydroxycitronellal plus the irritant sodium laurylsulfate. Contact Dermatitis 2003, 49:133-139.

20. Karlberg AT, Shao LP, Nilsson U, Gafvert E, Nilsson JL: Hydroperoxides in oxidized d-limonene identified as potent contact allergens. Arch Dermatol Res 1994, 286:97-103.

21. Matura M, Skold M, Borje A, Andersen KE, Bruze M, Frosch P, Goossens A, Johansen JD, Svedman C, White IR, Karlberg AT: Selected oxidized fragrance terpenes are common contact allergens. Contact Dermatitis 2005, 52:320-328.

22. Skold M, Hagvall L, Karlberg AT: Autoxidation of linalyl acetate, the main component of lavender oil, creates potent contact allergens. Contact Dermatitis 2008, 58:9-14.

23. Kantonales Laboratorium Basel Stadt. Analytik, Non food. http://www. kantonslabor-bs.ch.

24. EU Consumer Affairs, Rapex. http://www.rapex.eu.

25. Directive 2009/48/EC of the European Parliament and of the Council on the safety of toys. http://eur-lex.europa.eu/LexUriServ/LexUriServ.do? uri=OJ:L:2009:170:0001:0037:en:PDF.

26. Kalberlah F, Schwarz M, Bunke D, Wurbs J: Schadstoffbelastete Erzeugnisse im Verbraucherbereich: Wird REACH zu Verbesserungen führen? UWSF 2010, 22:188-204.

27. Schrader K, Domsch A: Cosmetology. In Theory and Practice. Edited by Ziolkowsky GmbH H. Augsburg: Verlag für chemische Industrie; 2005. Volume I to III.

28. Fischer R: Körperpflegejahrbuch. The Green Book of Cosmetics. Augsburg: Verlag für chemische Industrie; 2010.

29. Commission Decision 96/335/EC of 8 May 1996 establishing an inventory and a common nomenclature of ingredients employed in cosmetic products. Off J L 132, 01/06/1996, 1-684. http://eur-lex.europa. eu/LexUriServ/LexUriServ.do?uri=CELEX:31996D0335:EN:HTML.

doi:10.1186/2190-4715-24-37

Cite this article as: Klaschka: Dangerous cosmetics - criteria for classification, labelling and packaging (EC 1272/2008) applied to personal care products. Environmental Sciences Europe 2012 24:37.

\section{Submit your manuscript to a SpringerOpen ${ }^{\odot}$ journal and benefit from:}

- Convenient online submission

- Rigorous peer review

- Immediate publication on acceptance

- Open access: articles freely available online

- High visibility within the field

- Retaining the copyright to your article

Submit your next manuscript at $>$ springeropen.com 